\title{
Effect of the Routine Varicella Immunization on Herpes Zoster in Japan in the First Half of the Year
}

\author{
Tamie Sugawara ${ }^{*}$, Yasushi Ohkusa ${ }^{1}$, Miwako Kamei ${ }^{2}$ \\ ${ }^{1}$ National Institute of Infectious Diseases, Tokyo, Japan \\ ${ }^{2}$ School of Pharmacy, Nihon University, Chiba, Japan \\ Email: *tammy@nih.go.jp
}

How to cite this paper: Sugawara, T., Ohkusa, Y. and Kamei, M. (2018) Effect of the Routine Varicella Immunization on Herpes Zoster in Japan in the First Half of the Year. Journal of Biosciences and Medicines, 6, 30-36.

https://doi.org/10.4236/jbm.2018.611004

Received: October 12, 2018

Accepted: November 13, 2018

Published: November 16, 2018

Copyright ( $) 2018$ by authors and Scientific Research Publishing Inc. This work is licensed under the Creative Commons Attribution International License (CC BY 4.0).

http://creativecommons.org/licenses/by/4.0/

\section{Open Access}

\begin{abstract}
In Japan, herpes zoster is not monitored officially or nationwide. Recently, the databases of all electronic medical claims nationwide (NDBEMC) have been available for research. We use NDBEMC from April 2011 to March 2015. To evaluate the effects of initiation of routine immunization for varicella in children, we regressed the number of herpes zoster patients on the dummy variable for the routine immunization for varicella in children with and without a linear time trend. The estimated coefficient for the routine immunization for varicella was 0.5157 and its $p$-value was 0.001 . However, if the time trend was added as an explanatory variable, the estimated coefficient for the routine immunization for varicella changed to be -0.039 and its $p$-value was 0.384 . It means that the routine immunization for varicella was $7.8 \%$ higher after introduction than before. However, it was presumed to reflect such an upward trend.
\end{abstract}

\section{Keywords}

National Database of Electronic Medical Claims, Herpes Zoster, Routine Immunization, Varicella

\section{Introduction}

Herpes zoster, a common infectious disease related with varicella-herpes zoster virus, especially affects elderly people [1]-[10]. It causes a painful, blistering rash and can lead to postherpetic neuralgia, a persistent painful complication. However, in Japan, the Law Related to the Prevention of Infectious Diseases and Medical Care for Patients of Infections (The Infectious Diseases Control Law) has not included this disease in its surveillance. The official and nationwide epi- 
demiology of herpes zoster therefore remains unclear. Some few local, small, but long-term studies have examined herpes zoster. They provide some valuable evidence related to herpes zoster [6].

Recently, in Japan, all electronic medical claims nationwide (National Database of Electronic Medical Claims (NDBEMC)) have been disclosed as "Data of Medical Claims and Health Check-Ups for Metabolic Syndrome" from the Ministry of Health, Labor and Welfare. It covered $98.4 \%$ of all medical claims in 2015 [11]. All doctors must record a diagnosis on medical claim. Therefore, it must necessarily constitute the most reliable data source. This paper presents examination of the epidemiology of herpes zoster using NEBEMC.

In October 2014, routine immunization for varicella was introduced in Japan. Earlier studies predicted and subsequently found that immunization for varicella raises the prevalence of herpes zoster because of diminished opportunities to boost the immunity of elderly people [3] [12] [13] [14] [15]. However, other studies found no significant effect [16] [17] [18]. One mathematical model implied that its effect depends on the situation. Some cases showed no effect [19]. Unfortunately, such an effect has been confirmed in Japan yet to date. Therefore, this study was conducted to estimate its effect on the epidemic of herpes zoster in the first half of the year using NDBEMC.

\section{Materials and Methods}

\subsection{Data and Study Period}

From electronic medical claims data, NDBEMC can count patients who have been diagnosed as having the herpes zoster, excluding suspected cases. In May 2015 , the coverage of electronic medical claims was approximately $98.4 \%$ of all medical claims. NDBEMC data were those of April 2009 to March 2015. However, in 2009 and 2010, the coverage was, respectively only $52.1 \%$ and $81.4 \%$. Conversely, in April 2011, it increased to 93.1\% [11]. Therefore, we omit the low coverage period until March 2011. Then we adjust the number of patients by the coverage rate.

It is noteworthy that the number of patients in each month in NDBEMC should be regarded as the prevalence rate, not as the incidence, because the symptoms caused by herpes zoster typically continue for more than one month. For that reason, the same patients might appear in NDBEMC over several months. Herpes zoster is a common disease among elderly people. Therefore, we particularly focused 65 years old or older persons.

\subsection{Statistical Analysis}

We estimate the simple equation as

$$
r_{t}=\alpha+\beta d_{t}+\sum_{i=2}^{12} \gamma_{i t} m_{i t}+\varepsilon_{t}
$$

where, $r_{t}$ represents the prevalence rate of herpes zoster per 1000 population for people older than 65 years old divided by the coverage rate of NDBEMC, $d_{t}$ is a 
dummy variable for the initiation of the routine immunization for varicella: it is one from October 2014 and otherwise zero. Also, $m_{i t}$ is a dummy variable that represents the month.

Moreover, we add a linear trend to explanatory variables in Equation (1) as

$$
r_{t}=\alpha+\beta d_{t}+\sum_{i=2}^{12} \gamma_{i t} m_{i t}+T_{t}+\varepsilon_{t}
$$

where $T_{\mathrm{t}}$ represents a linear time trend.

\subsection{Ethical Considerations}

This study used only anonymous data that had been de-linked from individual patient information. Therefore, ethical issues related to medical institutions and pharmacies are unrelated to this study. The use of NDBEMC data by MK for this study was approved by the Ministry of Health, Labor and Welfare of Japan on July 27, 2016 (Research project: Estimation of the number of patients of infectious diseases).

\section{Results and Discussion}

Figure 1 showed the prevalence of herpes zoster, underscoring the seasonality clearly: it is low in January and February and high in September and October. It also shows an apparently upward trend before introduction of routine immunization of varicella for children. The average of the prevalence was 6.621 per 1000 elderly people. The estimation result shows that the estimated coefficient for the

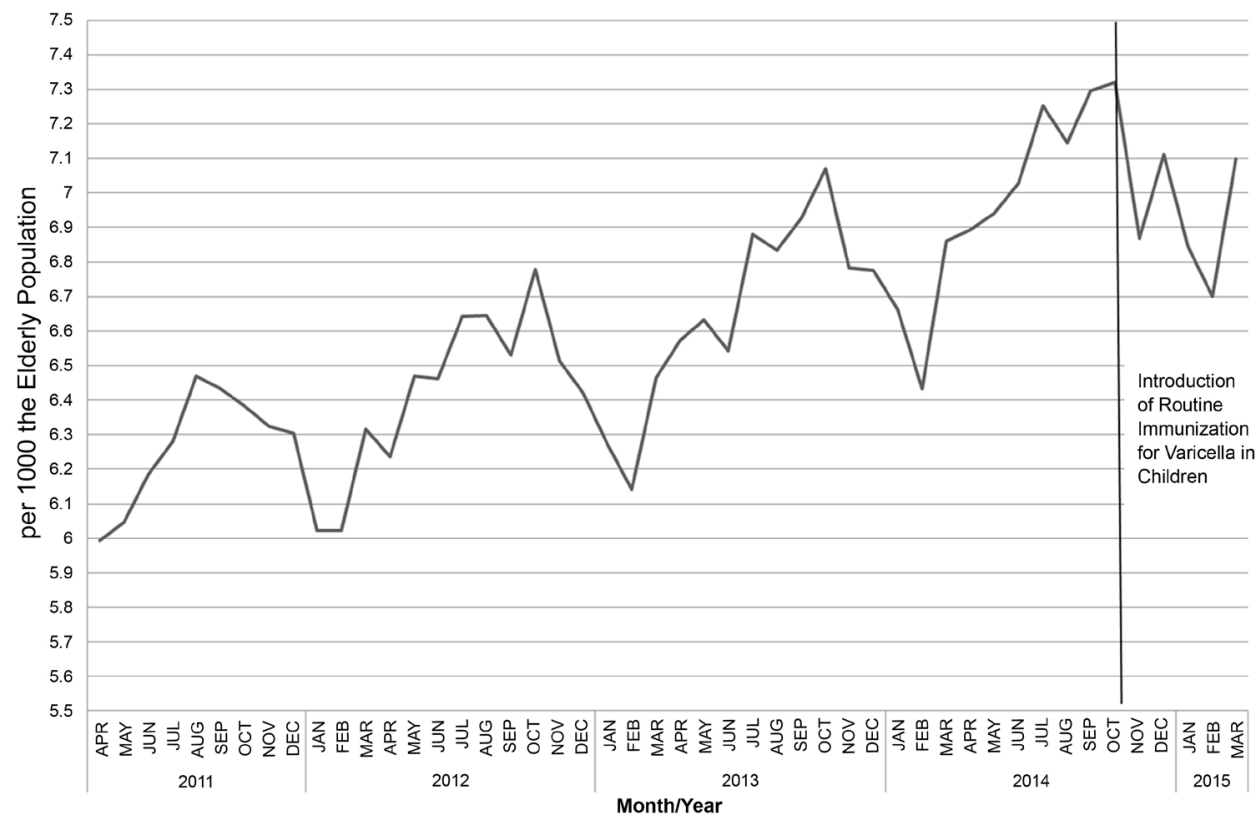

Figure 1. Prevalence of herpes zoster zoster in patients over 65 years old per 1000 population, divided by the NDBEMC coverage rate. Note: These numbers represent the total number of herpes zoster patients in NDBEMC, divided by the elderly population multiplied by 1000 , and divided by the coverage rate of NDBEMC. Vertical line indicates October, 2014 when introduction of routine immunization for varicella in children. 
initiation of the routine immunization for varicella was 0.5157 . Its $p$-value was 0.001 . The coefficient of determination was 0.6195 .

If we add the time trend as an explanatory variable into the estimation equation, then the estimated coefficient of linear trend was 0.023 . Its $p$-value was less than 0.0004 . However, the estimated coefficient for the initiation of the routine immunization for varicella was -0.039 . Its $p$-value was 0.384 . The fitness is quite high. The coefficient of determination was 0.9654 .

An earlier study conducted in Japan [10] found the incidence rate of herpes zoster in people older than 60 years old as around 7 - 8 per 1000 population in 1997-2011 in Miyazaki prefecture. The prevalence rate found in our study, 6.621, was comparable, but it was lower than the incidence in the US, which was 11.12 15.1 for elderly people older than 60 - 65 years old during 1992-2010 [18] [19]. In the US, routine varicella immunization for children had already been introduced in 1996. For that reason, those incidences might have been affected. If we adopt the varicella immunization effect on herpes zoster incidence in the US as $39 \%$, referring to results from an earlier study [18], and adjust those numbers, then the incidence of herpes zoster before the initiation of varicella immunization for children is expected to be 8.1 - 10.8. Despite such an adjustment, the incidence of herpes zoster in Japan by NDBEMC is apparently lower than that in the US.

Results show a higher value by 0.5157 after the introduction of routine immunization for varicella than that of the period before introduction. Its magnitude was $7.8 \%$ higher than in the before period, evaluated at its average. Therefore, we can infer that routine immunization for varicella raises the prevalence of herpes zoster significantly.

A similar earlier study [18] estimated its effect as $39 \%$. Our result is apparently much smaller. This discrepancy might result from the evaluation timing for initiation. We set it earlier and with a shorter duration. The effect might be larger than ours if we extend the study period.

However, as shown in Figure 1, the prevalence has an apparently upward trend even in the period before. Incidentally, if we add the trend into the estimation equation as an explanatory variable, then the dummy variable for the routine immunization for varicella is not significant anymore. Therefore, our obtained significant effect of routine immunization of herpes zoster on herpes zoster prevalence without a trend was presumed to reflect such an upward trend.

The potential reason for this upward trend was the decline of contact between elderly people and children who sometimes are infected with varicella in a house or community. If routine immunization of varicella raises the prevalence of herpes zoster, then such a decline of contact also raises the prevalence of herpes zoster. In other words, this decline of contact might dominate the effect of initiation of routine immunization for varicella.

Though it may be out of our concern, we also see the situation of varicella incidence in the same period. It was shown in Figure 2. Apparently, the curve has 


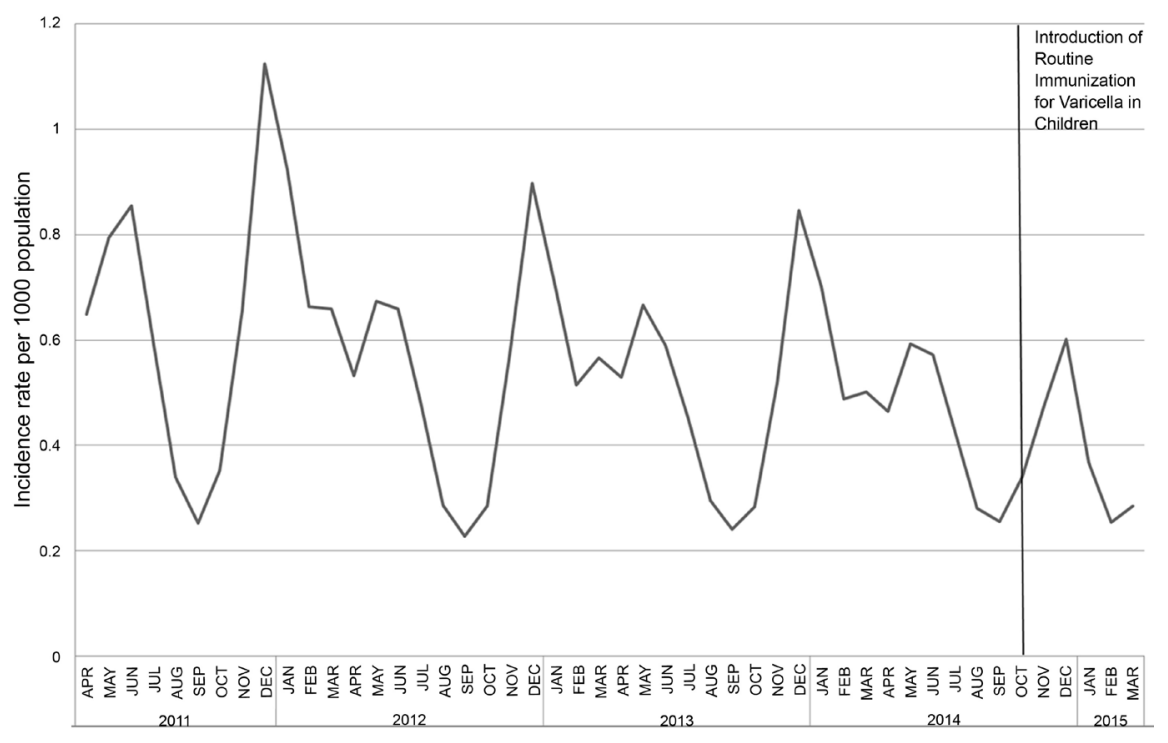

Figure 2. Incidence rate of varicella in patients per 1000 population, divided by the NDBEMC coverage rate. Note: These numbers represent the total number of herpes zoster patients in NDBEMC, divided by the population multiplied by 1000 , and divided by the coverage rate of NDBEMC. Vertical line indicates October, 2014 when introduction of routine immunization for varicella in children.

downward trend before the introduction of the routine immunization. It might reflect the declining in birth rate. Even though the reason of such a downward trend in varicella incidence was not clear, it should associate with the upward trend in herpes zoster prevalence irrelevantly with the introduction of the routine immunization.

\section{Conclusion}

We examined the effect of routine immunization of varicella on the prevalence of herpes zoster in the first half of the year using the most reliable data source of illness. Although a significant effect of routine immunization of varicella was found, the upward trend started before initiation might dominate the effect. We must monitor a longer period to distinguish the effects of routine immunization of varicella other than an upward trend.

\section{Acknowledgements}

We gratefully acknowledge the Ministry of Health, Labor and Welfare for granting us permission to use NDBEMC.

\section{Conflicts of Interest}

The authors declare no conflicts of interest regarding the publication of this paper.

\section{References}

[1] Brisson, M. and Edmunds, W.J. (2003) Epidemiology of Varicella-Zoster Virus in England and Wales. Journal of Medical Virology, 70, S9-S14. 
https://doi.org/10.1002/jmv.10313

[2] Garnett, G.P. and Grenfell, B.T. (1992) The Epidemiology of Varicella-Zoste Virus Infections: The Influence of Varicella on the Prevalence of Herpes Zoster. Epidemiology \& Infection, 108, 513-528. https://doi.org/10.1017/S0950268800050019

[3] Thomas, S.L., Wheeler, J.G. and Hall, A.J. (2002) Contacts with Varicella or with Children and Protection against Herpes Zoster in Adults: A Case-Control Study. Lancet, 360, 678-682. https://doi.org/10.1016/S0140-6736(02)09837-9

[4] Yih, W.K., Brooks, D.R., Lett, S.M., Jumaan, A.O., Zhang, Z., Clements, K.M., et al. (2005) The Incidence of Varicella and Herpes Zoster in Massachusetts as Measured by the Behavioral Risk Factor Surveillance System (BRFSS) during a Period of Increasing Varicella Vaccine Coverage, 1998-2003. BMC Public Health, 5, 68. https://doi.org/10.1186/1471-2458-5-68

[5] Brisson, M., Edmunds, W.J., Law, B., Gay, N.J., Walld, R., Brownell, M., et al. (2001) Epidemiology of Varicella Zoster Virus Infection in Canada and the United Kingdom. Epidemiology \& Infection, 127, 305-314.

https://doi.org/10.1017/S0950268801005921

[6] Brisson, M., Gay, N.J., Edmunds, W.J. and Andrews, N.J. (2002) Exposure to Varicella Boosts Immunity to Herpes-Zoster: Implications for Mass Vaccination against Chickenpox. Vaccine, 20, 2500-2507. https://doi.org/10.1016/S0264-410X(02)00180-9

[7] Goldman, G.S. (2005) Cost-Benefit Analysis of Universal Varicella Vaccination in the U.S. Taking into Account the Closely Related Herpes-ZOSTER epidemiology. Vaccine, 23, 3349-3355. https://doi.org/10.1016/j.vaccine.2003.10.042

[8] Arruti, M., Piñeiro, L.D., Salicio, Y., Cilla, G., Goenaga, M.A. and López de Munain, A. (2017) Incidence of Varicella Zoster Virus Infections of the Central Nervous System in the Elderly: A Large Tertiary Hospital-Based Series (2007-2014). Journal of Neurovirology, 23, 451-459.

[9] Varghese, L., Standaert, B., Olivieri, A. and Curran, D. (2017) The Temporal Impact of Aging on the Burden of Herpes Zoster. BMC Geriatrics, 17, 30. https://doi.org/10.1186/s12877-017-0420-9

[10] Toyama, N. and Shiraki, K. (2009) Epidemiology of Herpes Zoster and Its Relationship to Varicella in Japan: A 10-Year Survey of 48,388 Herpes Zoster Cases in Miyazaki Prefecture. Journal of Medical Virology, 81, 2053-2058. https://doi.org/10.1002/jmv.21599

[11] Akabane, N. (2018) Utilization of Big Data in Medicine, Especially Using National Database of Electronic Medical Claims and Health Check-Up for Metabolic Syndrome. (In Japanese) https://www.jahis.jp/files/user/5-1\%20\%E8\%B5\%A4\%E7\%BE\%BD\%E6\%A0\%B9\%E 5\%AE\%A4\%E9\%95\%B7\%E7\%89\%B9\%E5\%88\%A5\%E8\%AC\%9B\%E6\%BC\%94\%E8 \%B3\%87\%E6\%96\%99.pdf

[12] Gershon, A.A., LaRussa, P., Steinberg, S., et al. (1996) The Protective Effect of Immunologic Boosting against Zoster: An Analysis in Leukemic Children Who Were Vaccinated against Chickenpox. The Journal of Infectious Diseases, 173, 450-453. https://doi.org/10.1093/infdis/173.2.450

[13] Hales, C.M., Harpaz, R., Joesoef, M.R., et al. (2013) Examination of Links between Herpes Zoster Incidence and Childhood Varicella Vaccination. Annals of Internal Medicine, 159, 739-745. https://doi.org/10.7326/0003-4819-159-11-201312030-00006

[14] Donahue, J.G., Kieke, B.A., Gargiullo, P.M., et al. (2010) Herpes Zoster and Expo- 
sure to the Varicella Zoster Virus in an Era of Varicella Vaccination. American Journal of Public Health, 100, 1116-1122.

https://doi.org/10.2105/AJPH.2009.160002

[15] Chaves, S.S., Santibanez, T.A., Gargiullo, et al. (2007)Chickenpox Exposure and Herpes Zoster Disease Incidence in Older Adults in the U.S. Public Health Reports, 122, 155-159. https://doi.org/10.1177/003335490712200204

[16] Poletti, P., Melegaro, A., Ajelli, M., et al. (2013) Perspectives on the Impact of Varicella Immunization on Herpes Zoster. A Model-Based Evaluation from Three European Countries. PLoS ONE, 8, e60732. https://doi.org/10.1371/journal.pone.0060732

[17] Oxman, M.N., Levin, M.J., Johnson, G.R., et al. (2005) A Vaccine to Prevent Herpes Zoster and Postherpetic Neuralgia in Older Adults. New England Journal of Medicine, 352, 2271-2284. https://doi.org/10.1056/NEJMoa051016

[18] Tseng, H.F., Smith, N., Harpaz, R., et al. (2011) Herpes Zoster Vaccine in Older Adults and the Risk of Subsequent Herpes Zoster Disease. JAMA, 305, 160-166. https://doi.org/10.1001/jama.2010.1983

[19] Langan, S.M., Smeeth, L., Margolis, D.J. and Thomas, S.L. (2013) Herpes Zoster Vaccine Effectiveness against Incident Herpes Zoster and Post-Herpetic Neuralgia in an Older US Population: A Cohort Study. PLoS Medicine, 10, e1001420. https://doi.org/10.1371/journal.pmed.1001420 